10 Wiles R. Empowering practice nurses in the follow-up of patients with established heart disease: lessons from patients' experiences. J Adv Nurs 1997;26:729-35.

11 Patton M Qualitative evaluation and research methods. Newbury Park, CA Sage, 1990.

12 Strauss A, Corbin J. Basics of qualitative research: grounded theory procedures and techniques. London: Sage, 1990

13 Southampton heart integrated care programme. Information for patients. Southampton: Primary Medical Care Group, University of Southampton, 1994.

14 Pope C, Mays N. Reaching the parts other methods cannot reach: an introduction to qualitative methods in health and health services research. BMJ 1995;311:42-5.

15 Johnson A, Wadsworth J, Wellings K, Field J. Sexual attitudes and lifestyles. Oxford: Blackwell Scientific, 1994

16 Little P, Williamson I, Warner G, Gould C, Gantley M, Kinmonth A-I Open randomised trial of prescribing strategies in managing sore throat BMJ 1997;314:722-77.

17 Bloor MJ, Venters GA, Samphier ML. Geographical variation in the incidence of operations on the tonsils and adenoids: an epidemiological and sociological investigation. J Laryngol Otology 1976;92:791-801, 883-95.
18 Brannen J, Moss P. Managing mothers: dual earner households after maternity leave. London: Unwin Hyman, 1991.

19 Grimshaw JM, Russell IT. Effect of clinical guidelines on medical practice: a systematic review of rigorous evaluations. Lancet 1993;342:1317-22.

20 Schwarzer R. Self-efficacy in the adoption and maintenance of health behaviours: theoretical approaches and a new model. In: Schwarzer R, ed. Self-efficacy: thought control of action. London: Hemisphere; 1992:217-43.

21 Prochaska JO, DiClemente CC. Stages and processes of self-change of smoking: toward an integrative model of change. J Consult Clin Psychol 1983;51:390-5

22 Rollnick S, Heather N, Bell A. Negotiating behaviour change in medical settings: the development of brief motivational interviewing. $J$ Ment Health 1992;1:25-37.

23 Oakley A. Social support and motherhood. Oxford: Blackwell, 1992.

24 Stott NCH, Rollnick S, Rees M, Pill RM. Innovation in clinical method, diabetes care and negotiating skills. Fam Pract 1995;12:413-8

25 Box GEP. Evolutionary operation: a method for increasing industrial productivity. Appl Stat 1956;vi(2):81-101.

(Accepted 10 February 1999)

\section{An evidence based approach to reducing antibiotic use in children with acute otitis media: controlled before and after study}

\author{
Christopher Cates
}

Two recent reviews questioned the routine use of antibiotics in the initial management of acute otitis media. ${ }^{12}$ My practice partners and I responded to the reviews by changing our policy, with the aim of reducing such prescribing in children. We measured the change one year after adopting the new policy.

\section{Methods and results}

From July 1997 my practice partners and I changed our policy on routine prescription of antibiotics in the initial management of acute otitis media in children. In children who were not particularly ill we gave the parents a handout that summarised the limited benefit of antibiotics on the basis of the data presented in the Cochrane review. ${ }^{1}$ We advised parents to give regular paracetamol suspension; we also offered an antibiotic prescription but asked the parents to keep it for a day or two. They could redeem it at a pharmacy if the child

A local practice acted as a concurrent control. Both practices use amoxicillin suspension as the antibiotic of choice in children with acute otitis media, and, although the doctors in the control practice were aware of the new evidence, they did not use the handout or use deferred prescriptions. Monthly prescribing rates of all amoxicillin suspensions were obtained for each practice from the district health authority. The 12 months before July 1997 were used for baseline comparison, and the following 12 months were used to assess the impact of our change in policy. Both practices had closely similar list sizes (about 11000 patients) throughout the study. As there was seasonal and annual variation in prescribing levels, monthly odds of prescriptions issued in relation to the national total were calculated for each practice; these were weighted and pooled by using the Mantel-Haenszel method. ${ }^{3}$ did not got better over this period.
Prescriptions for other antibiotic suspensions were also checked in our practice by comparing figures from the reports on level 3 prescribing analysis and cost data (PACT) with national figures, to check that other antibiotics were not being substituted for amoxicillin.

The table shows the monthly prescriptions for amoxycillin suspension for each practice, along with national totals. The median number of prescriptions per month in our practice fell from 75 to 47 after the change (median difference -30.5 (95\% confidence interval -14 to $-31,2 \mathrm{P}=0.0065$, Mann-Whitney $\mathrm{U}$ test). Compared with the national levels, the fall in prescribing amoxicillin suspension in our practice was $-32 \%(-25 \%$ to $-39 \%)$ and in the control practice was $-12 \%(-4 \%$ to $-20 \%)$.

Monthly totals of prescriptions for all amoxicillin suspensions for 12 months before (1996-7) and after (1997-8) new prescribing policy was introduced

\begin{tabular}{|c|c|c|c|c|c|c|}
\hline \multirow[b]{2}{*}{ Month } & \multicolumn{2}{|c|}{ Practice using new policy } & \multicolumn{2}{|c|}{ Control practice } & \multicolumn{2}{|c|}{ Nationally } \\
\hline & Before & After & Before & After & Before & After \\
\hline July & 68 & 55 & 68 & 66 & 392367 & 364831 \\
\hline August & 35 & 31 & 35 & 26 & 220606 & 214292 \\
\hline September & 74 & 33 & 56 & 40 & 367901 & 366957 \\
\hline October & 65 & 45 & 72 & 54 & 429828 & 503459 \\
\hline November & 106 & 62 & 150 & 90 & 502174 & 530556 \\
\hline December & 162 & 117 & 169 & 155 & 869621 & 752960 \\
\hline January & 95 & 49 & 85 & 72 & 634195 & 489216 \\
\hline February & 86 & 78 & 83 & 91 & 538509 & 591498 \\
\hline March & 80 & 49 & 86 & 74 & 470010 & 515528 \\
\hline$\overline{\text { April }}$ & 70 & 44 & 64 & 66 & 392452 & 354032 \\
\hline May & 76 & 39 & 72 & 50 & 442111 & 323566 \\
\hline June & 71 & 37 & 51 & 51 & 345765 & 369194 \\
\hline Median & 75 & 47 & 72 & 66 & 435970 & 429205 \\
\hline
\end{tabular}

$\%$ change from previous $\quad-32 \%(-39 \%$ to $-25 \%) \quad-12 \%(-20 \%$ to $-4 \%)$

${ }^{*}$ Change in pooled odds ratios for the odds of prescriptions issued each month related to the national total for that month and compared with the odds for the same month in the previous year (the Mantel-Haenszel method was used to weight and pool the odds ratios).

Manor View Practice, Bushey Health Centre, Bushey, WD2 2NN Christopher Cates, chriscates@ email.msn.com

BMJ 1999;318:715-6 year $(95 \% \mathrm{Cl})^{*}$ Hertfordshire general practitioner 
In the six months after the change in policy the number of antibiotic suspensions prescribed in our practice was $19 \%$ lower (16\% to $21 \%)$ than in the same six months of the previous year. Over this period national prescribing of all antibiotic suspensions fell by $3 \%{ }^{4}$

\section{Comment}

Before my partners and I changed our policy, acute otitis media accounted for over half of all antibiotics prescribed for children in our practice. After our change in policy the proportion fell to a third, and as a consequence total antibiotic use for all infections in childhood fell by one fifth. As the evidence is not yet available to identify which children with acute otitis media benefit most from antibiotics we deferred prescriptions in those who were not systemically unwell (as suggested in the editorial comment accompanying one of the reviews in the $B M J^{5}$ ).

We found that most parents welcomed the written handout. The deferred prescription also acted as a safety net while they waited to see if the ear infection would resolve by itself and was often not redeemed. We are continuing with this policy, and in the current battle against antimicrobial resistance we would commend this approach to initial management of acute otitis media as a way of reducing the antibiotic load on children in the community.
A copy of the leaflet given to patients can be supplied by the author.

I thank my partners (Drs T Boyd, B Bintcliffe, J Glover, M Buist, and P Davis) for taking part in the study and the control practice for allowing me the use of their prescribing data; Mrs Frances Wilson (West Hertfordshire Health Authority) for providing prescribing data for both practices; Dr John Ferguson (medical director of the Prescription Pricing Authority, Newcastle upon Tyne) and Mr A M Savva (Statistics Division 1E of the Department of Health) for providing the national figures; Iain Chalmers and Professor C Del Mar for helpful comments; and Dr M Cucherat for use of the software package to perform the Mantel-Haenszel analysis.

Contributors: $\mathrm{CC}$ had the original idea for the study, collected and analysed the data, and drafted and revised the paper. His partners helped him to construct the handout. CC is the guarantor for the paper.

Funding: NHS Executive (North Thames) provided funding for protected time for $\mathrm{CC}$.

Competing interests: None declared.

1 Glasziou PP, Hayem M, Del Mar CB. Antibiotic versus placebo for acute otitis media in children. In: Cochrane Collaboration. Cochrane Library. Issue 1. Oxford: Update Software, 1997.

2 Froom J, Culpepper L, Jacobs M, DeMelker RA, Green LA, van Buchem $\mathrm{L}$, et al. Antimicrobials for acute otitis media? A review from the International Primary Care Network. BMJ 1997;315:98-102

3 Cucherat M, Boissel JP, Leizorovicz A. Easy MA. A programme for the meta-analysis of clinical trials. Computer Methods and Programs in Biomedicine 1997:53:187-90.

4 Prescription cost analysis (England). London: Department of Health: 1996, 1997.

5 Majeed A, Harris T. Acute otitis media in children. BMJ 1997;315:321-2.

(Accepted 10 December 1998)

\section{When I use a word ... Please, please me}

Many words change their meaning with the years, and in some cases the new meaning is the opposite of the old, or at least at a tangent to it. A well known example is prestigious, which originally meant deceitful and now means esteemed. I am not sure, but I think that placebo may be in that camp.

The standard etymology is that placebo is the first person future indicative of the Latin word placeo, I please- - that is, placebo $=\mathrm{I}$ shall please. But I don't think it's as simple as that.

The word first entered the English language through its erroneous use in a Latin translation of verse 9 of Psalm 116, which in Hebrew transliteration is "et'halekh liphnay adonai b'artzot hakhayim." This is correctly translated in the King James version as "I will walk before the Lord in the land of the living," but the Latin version in the Vulgate of St Jerome is "Placebo Domino in regione vivorum." This ("I shall please the Lord in the land of the living") is not a correct translation of the Hebrew, but perhaps Jerome reasoned that anyone who walked before (or as the Revised English Bible has it "in the presence of") the Lord would please Him, and used the word placebo for the sake of euphony or metre (the Latin line happens to be a dactylic pentameter, like the dactylic hexameters used in Greek and Latin epic verse, such as Virgil's Aeneid).

Because the verse was used in the Vespers of the Office for the Dead, the word placebo, with which it began, became in the thirteenth century the name of that service. And because some people attended the service and sang the Placebo, hoping to be rewarded by a dead person's relatives, the word came to mean a sycophant. As Chaucer wrote in The Parson's Tale: "Flatterers are the Devil's chaplains, always singing Placebo."

Then suddenly the word appeared in the "enlarged and improved" second edition of George Motherby's New Medical Dictionary of 1785 (not having appeared in the first edition of 1775), where it was defined as "a common place method or medicine." Why placebo came to have that meaning at that time is not clear. Common-place (usually spelt with a hyphen in those days) meant then, as it does now, ordinary, unoriginal, trivial, and so Motherby's definition suggests neither the modern meaning of placebo nor its traditional derivation ("I shall please"). However, the word "placere" also meant "to be popular," so a placebo may originally have been a drug that was of sufficient efficacy, or perceived efficacy, to be popular.

The word next appears in 1811 in Hooper's Medical Dictionary: "any medicine adapted more to please than benefit the patient." This sounds closer to our modern use of the word, and it is possible that a change in meaning may have taken place at about the turn of the nineteenth century, perhaps through a misunderstanding over the original derivation; or perhaps through a form of medical snobbery, the assumption being that anything popular couldn't be of much value; or possibly harking back to the old idea of sycophancy - that is, a medicine that flattered the user into believing it to be effective.

So perhaps from being a popular medicine with a useful if minor effect, a placebo became a medicine without any effect at all, or not one that you could rely on. More medical examples of the use of the word before 1785 or at around the turn of the nineteenth century might throw some light on the matter.

Jeff Aronson, clinical pharmacologist, Oxford

We welcome articles of up to 600 words on topics such as A memorable patient, A paper that changed my practice, My most unfortunate mistake, or any other piece conveying instruction, pathos, or humour. If possible the article should be supplied on a disk. Permission is needed from the patient or a relative if an identifiable patient is referred to. We also welcome contributions for "Endpieces," consisting of quotations of up to 80 words (but most are considerably shorter) from any source, ancient or modern, which have appealed to the reader. 